\title{
CONDUTAS TERAPÊUTICAS E DE SUPORTE NO PACIENTE COM DENGUE HEMORRÁGICO*
}

\author{
Aluizio Prata', Amélia P. A. Travassos da Rosa², Glória Teixeira ${ }^{3}$, Ivo Castelo \\ Branco Coêlho ${ }^{4}$, José Tavares-Neto ${ }^{5}$, Juarez Dias ${ }^{6}$, Luiz Tadeu M. Figueiredo \\ Reynaldo Dietze ${ }^{8}$, Rogério Valls $^{9}$, Sonia Maris ${ }^{10}$, Wilson Alecrim ${ }^{11}$
}

Foram revistas as bases fisiopatológicas da infecção pelo vírus do dengue, bem como os critérios de diagnóstico e a conduta terapéutica, especialmente em pacientes com a febre hemorrágica do dengue (FHD). Os autores chamam a atenção sobre o fluxo no atendimento do paciente com a $F H D$, com ou sem choque, notadamente quanto à relevância da organização da rede de serviços de saúde. Os pacientes com FHD são atendidos em unidades de saúde de vários níveis de complexidade. No entanto, a rede de serviços local deve ser adaptada, ocorrendo casos clínicos suspeitos de FHD. Desta forma, os autores anexam fluxos de atendimento, nos quais a unidade de terapia intensiva não é local exclusivo de atendimento e, nesses mesmos fluxos, citam as condutas terapéuticas com base na evolução clínica do paciente. Os autores também enfatizam os criterios de diagnóstico (e sinais de alerta) das formas clínicas graves; os critérios de alta destes casos e citam, entre outros parâmetros, a avaliação da hemoconcentração usando o índice hematocrito/hemoglobina (acima de 3,5). O grupo técnico faz também algumas recomendaçð̃es, inclusive sobre a necessidade dos órgăos gestores promoverem a qualificação de serviços e treinamento de pessoal.

\footnotetext{
* Trabalho realizado durante o "Curso Sobre Dengue: clínica e terapêutica", em Salvador-BA, de 31/07 a 04/08/1997, organizado pela Sociedade Brasileira de Medicina Tropical (Regional-BA) e com o patrocínio da Secretaria da Saúde do Estado da Bahia (SESAB), da Fundaçáo Nacional de Saúde (FNS), da Organizaçáo Pan-Americana de Saúde (BrasiliaDF) e do Laboratório Janssen-Cilag.

1.Professor Titular da Faculdade de Medicina do Triângulo Mincıro (Uberaba-MG) e Presidente da Comissão de Acompanhamento e Avaliação do Programa de Erradicação do Aedes aegypti do Ministério da Saúde; 2.Pesquisadora Titular do Instituto Evandro Chagas (Belém-PA); 3.Professora Adjunta do Instituto de Saúde Coletiva da UFBA (SalvadorBA); 4.Professor Adjunto-doutor da Faculdade de Medicina da UFCE (Fortaleza-CE); 5.Professor Adjunto-doutor da Faculdade de Medicina da UFBA (Salvador-BA); 6.Médico-Sanitarista da Secretaria Estadual da Saúde da Bahia e Médico do Hospital Universitário Professor Edgard Santos da UFBA (Salvador-BA); 7.Professor Adjunto-doutor da Faculdade de Medicina de Ribeiráo Preto/USP (Ribeiráo Preto-SP); 8.Professor Adjunto-doutor da Faculdade de Medicina da UFES (Vitória-ES); 9.Pesquisador Adjunto da Fundaçăo Oswaldo Cruz (FIOCRUZ) e Médico do Hospital Evandro Chagas (Rio de Janeiro-RJ); 10.Professora Assistente da Universidade Federal Fluminense e Médica da Fundaçáo Municipal de Saúde de Niterói (Niterói-RJ); 11.Professor Titular da Faculdade de Ciências da Saúde da UFAM e Diretor do Instituto de Medicina Tropical do Amazonas (Manaus-AM).
}

Endereço para correspondência: Prof. José Tavares-Neto. Faculdade de Medicina da UFBA, Av. Reitor Miguel Calmon s/no, Campus Canela, 40110-100, Salvador, Bahia 


\section{Introdução}

O Grupo Técnico, responsável pela elaboração deste documento, entende que a principal forma de enfrentamento do dengue no país continua sendo a interrupção do elo vulnerável da sua cadeia de transmissão, ou seja, a erradicação do Aedes aegypti, e todos os esforços devem ser feitos neste sentido. Entretanto, pelas dificuldades políticas, administrativas e financeiras que o Plano Diretor de Erradicaçáo vem atravessando, e pela magnitude da tarefa, infere-se que a eliminação da circulaçáo viral não ocorrerá $\mathrm{em}$ um curto espaço de tempo. Nestas circunstâncias, permanece o risco potencial de ocorrência de graves epidemias de dengue hemorrágico, como a que foi verificada em Cuba em 1981, com magnitude que pode ultrapassar a capacidade de atendimento da rede de serviços de saúde. Além disso, o Grupo Técnico considerou elevado o risco de reurbanização do vírus da febre amarela no Brasil.

Este documento visa contribuir para a melhoria da atenção às populaçōes das áreas com circulação viral, atualizando os conhecimentos sobre o diagnóstico e tratamento das formas graves do dengue. Por outro lado, além de oferecer subsídios técnicos e científicos para os profissionais de saúde, tem-se também o objetivo de colocar esse problema na agenda de discussão e planejamento dos dirigentes do sistema de saúde do país, visando minimizar a morbimortalidade que essa doença poderá ocasionar.

\section{Situação Epidemiológica}

A primeira epidemia de dengue com isolamento viral no Brasil ocorreu em 1981/ 1982, em Boa Vista-RR, quando os sorotipos DEN-1 e DEN-4 foram responsáveis pela infecção de 12.000 pessoas.

A partir de 1986, há o registro de epidemia de dengue no Estado do Rio de Janeiro causada pelo sorotipo DEN-1 e que, rapidamente, em 1986/1987, causou epidemias em quatro Estados (RJ, PE, AL, CE) e a transmissão localizada em mais três Estados (SP, MG, BA). Nessa ocasião, as açóes de combate ao Ae. aegypti foram intensificadas, porém a circulação viral não foi interrompida. As epidemias tiveram caráter explosivo; com a diminuição paulatina de susceptíveis ao sorotipo envolvido houve reduçáo marcante do número de casos notificados nas localidades com transmissão ativa nos anos de 1987/1988. Todavia, as medidas adotadas para combate ao vetor foram insuficientes e sem a devida continuidade e, com o passar do tempo, observou-se expansāo do número de municípios do Brasil com transmissão do vírus do dengue.

A partir de 1990, quando se identificou a circulação do sorotipo DEN-2(1) no Estado do Rio de Janeiro, a situação do dengue tornouse mais preocupante, pelo crescente risco de surgimento das formas graves da doença. Neste período, começaram a ser registrados os primeiros casos e óbitos por dengue hemorrágico no Rio de Janeiro.

A circulação dos sorotipos DEN-1 e DEN-2 continuou e, no período de 1986 a 1995, foram notificados no país aproximadamente 472.635 casos de dengue, com registro de dengue hemorrágico em 1990/ 1991 (Rio de Janeiro - 462 casos, e 8 óbitos) e 1994 (Fortaleza - 25 casos, e 12 óbitos).

Em 1994 houve epidemia de dengue le 2 no Ceará, predominando o sorotipo DEN-2. Posteriormente, o inquérito sorológico de uma amostra estratificada (1.341 indivíduos), por local de residência em Fortaleza-CE, mostrou que a população acometida foi estimada em 660.000 habitantes, com incidência de 1486,88 / 100.000 habitantes. Os resultados deste inquérito sorológico também evidenciaram que a população susceptível foi de $56 \%$ do total de habitantes de Fortaleza.

Em 1996, todos os Estados brasileiros, com exceção do Amapá, tiveram municípios infestados pelo Ae. aegypti, com registro de 180.392 casos distribuídos em 19 Estados, e

(1) Em 1989, o Laboratório de Arbovírus do Instituto Evandro Chagas isolou em Belém o sorotipo DEN-2 de paciente procedente de Angola, caracterizado como genotipo África (Burkina Faso). 
predomínio da transmissão na região Nordeste. Também em 1996, foram notificados 63 casos de Febre Hemorrágica do Dengue (FHD) no Rio de Janeiro e confirmados 6 casos em Pernambuco.

Em 1997, todos os Estados foram infestados pelo Ae. aegypti e, até a semana epidemiológica 25 (terceira semana de junho), houve o registro parcial de 138.990 casos notificados de dengue e de 15 casos confirmados de Febre Hemorrágica do Dengue (FHD) - 6 casos em Pernambuco e 9 no Rio Grande do Norte, além de casos em investigação na Paraíba. No início do ano, no Distrito Federal, foram registrados os primeiros casos autóctones de dengue.

\section{Impacto das Epidemias de Dengue}

A transcendência de um agravo à saúde é mensurada pela gravidade e pelo valor social que representa à sociedade, ou seja, pelo impacto atual ou potencial e suas repercussóes no desenvolvimento sócio-econômico. Pelo exposto no item anterior verifica-se a intensa e contínua circulação dos sorotipos 1 e 2 do dengue em extensas áreas do território nacional, atingindo pequenas cidades e grandes metrópoles, o que evidencia a possibilidade concreta de aumento da ocorrência de formas graves e potencialmente letais.

Tem-se minimizado as repercussōes sociais e econômicas dessas infecçóes, particularmente quando da ocorrência das primeiras epidemias com circulação de um único sorotipo do vírus. Entretanto, mesmo nas primeiras infecçóes, que geralmente se apresentam sob a forma de epidemias explosivas, são consideráveis os prejuízos decorrentes do absenteísmo coletivo ao trabalho e às escolas, além do desconforto e espoliaçáo protéico-calórica causados aos indivíduos.

Por outro lado, a manutençáo dos fatores determinantes e condicionantes da circulação viral vem favorecendo o aparecimento das formas hemorrágicas da doença, modificando o perfil de gravidade $e$, conseqüentemente, o impacto sócio-econômico das epidemias no Brasil.

De acordo com a atual situação epidemiológica, verifica-se que o Brasil tem a maior concentração de indivíduos susceptíveis no mundo, sob risco de epidemias de dengue hemorrágico. Apesar disso, até o momento temse registrado relativamente poucos casos desta forma da doença. A expansão e a persistência de circulação dos sorotipos 1 e 2 , aliadas à possibilidade de introdução dos sorotipos $3 \mathrm{e}$ 4 , impóe que se coloque este problema na agenda de planejamento dos dirigentes da área de saúde coletiva e de atençáo individual. Também a infestação maciça do território nacional pelo Ae. Aegypti oferece risco elevado da circulação do vírus da febre amarela nas áreas urbanas do Brasil.

Existem duas possibilidades de apresentação epidemiológica das epidemias de dengue hemorrágico. A primeira é semelhante ao maior evento ocorrido nas Américas, que foi a explosiva epidemia de Cúba em 1981, com registro de 344.203 notificaçōes, quando foi instituído um programa de hospitalização em massa (116.143 internaçốes). A segunda é a forma de apresentação epidemiológica das manifestaçóes hemorrágicas, que vêm ocorrendo em outros países da América Latina (Venezuela, Brasil, Nicáragua, Porto Rico), e mais recentemente em Cuba, que corresponde ao aparecimento de um número mais limitado de casos em áreas onde a infecção das formas clássicas está ocorrendo sob a forma epidêmica ou endêmica.

Em qualquer das duas situações, as repercussōes econômicas para o Brasil nos próximos anos serão consideráveis, em virtude da necessidade de capacitação de recursos humanos e adequaçáo da rede de serviços de saúde para atenção aos pacientes, visando minimizar a letalidade da doença através de um sistema de atendimento de qualidade. A nãoinstituição deste sistema resultará em impacto social imensurável, em virtude das altas taxas de letalidade que poderão ocorrer na ausência de assistência médica adequada. Exemplo dessa 
natureza já foi verificado na epidemia de 1994 no Ceará, onde se registraram 25 casos com 12 óbitos (taxa de letalidade próximo a $50 \%$ ), quando o esperado era inferior a $1 \%$ na vigência de diagnóstico e tratamento ágeis e eficientes.

A atenção aos pacientes com suspeita de dengue hemorrágico pode ser feita em serviços de saúde de pequena complexidade, desde que os profissionais estejam atentos e capacitados a efetuar o diagnóstico e tratamento. Conseqüentemente, tais medidas reduzirão o custo médico-social, através da diminuição dos óbitos e do uso inadequado de serviços de grande complexidade, como unidades de terapia intensiva.

\section{Fisiopatogenia}

Os vírus do dengue, após serem inoculados pela picada do mosquito, fazem uma primeira replicação em células musculares estriadas, lisas e fibroblastos, bem como em linfonodos regionais. Seguindo-se a esta replicação, inicia-se o período de viremia, que dissemina $o$ vírus por todo o organismo.

Os sintomas gerais do dengue, com febre e mal-estar, surgem após um período de incubação de 2 a 7 dias, coincidindo com a viremia. Esses sintomas relacionam-se a níveis séricos elevados de citocinas liberadas por macrófagos ao interagirem com linfócitos $\mathrm{T}$ (LT) auxiliares (helper) ativados. Observam-se altos teores séricos de IL-2 e de seu receptor solúvel, de CD4, IFN-símbolo 103 |f "Symbol" |s 12, IFN-símbolo 97 |f “Symbol” |s 12 (com elevação mantida até a convalescença), TNFsímbolo 97 \f "Symbol" |s 12, IL-1símbolo 98 If "Symbol" is 12 e PAF. A leucopenia e a discreta e transitória depressão medular que se apresentam nestes casos também relacionam-se aos altos teores de citocinas macrofágicas. As mialgias são conseqüentes, em parte, da multiplicação viral no próprio tecido muscular. O acometimento dos músculos óculo-motores é responsável pela cefaléia retro-orbitária, apresentada pela maioria dos pacientes.

A febre do dengue, nas formas oligossintomática e clássica, é auto-limitada e o desaparecimento da doença coincide com o aparecimento de vigorosa resposta imune. Os anticorpos, principalmente os que se ligam a epitopos da proteína $\mathrm{E}$, promovem lise do envelope viral ou bloqueio de seus receptores com conseqüente neutralização viral. Os epitopos da proteína $\mathrm{E}$ definem a produção de anticorpos específicos para o sorotipo viral. Podem ser detectados por múltiplos testes sorológicos (ensaios imuno-enzimáticos e de imunofluorescência; testes de neutralização, de inibição da hemaglutinação e de facilitação da infectividade).

Nos pacientes com dengue, a resposta humoral produzida por plasmócitos resultantes da ativação de linfócitos $\mathrm{B}$ costuma ser vigorosa. Os anticorpos IgM específicos podem ser detectáveis a partir do $4^{\circ}$ dia após o início dos sintomas, atingindo os níveis mais elevados por volta do $7^{\circ}$ ou $8^{\circ}$ dia e declinando lentamente, passando a não ser detectáveis entre 60 e 90 dias. Os anticorpos IgG específicos são observados, em níveis baixos, a partir do $4^{\circ}$ dia após o início dos sintomas, ou mesmo antes, se o paciente teve outro episódio de infecção por Flapipirus. Esses anticorpos IgG elevam-se gradualmente, atingindo altos títulos em duas semanas, e mantêm-se detectáveis por vários anos, conferindo imunidade contra o tipo infectante provavelmente por toda a vida.

$\mathrm{Na}$ Febre Hemorrágica do Dengue (FHD) e na Síndrome de Choque do Dengue (SCD), há outra resposta imune ao vírus do dengue que é paradoxal, ou seja, prejudica o hospedeiro infectado. Esta resposta pode ser observada em dois grupos de indivíduos: (i) acima de um ano de idade com uma segunda infecçáo por dengue (mais de $90 \%$ dos casos) e (ii) em crianças, menores de um ano, infectadas pela primeira vez, filhos de mães possuidoras de anticorpos para dengue. A importância da infecção secundária ou terciária por dengue, aumentando o risco de FHD/SCD, foi corroborada em estudo mais recente efetuado em Myanmar.

No primeiro grupo, que corresponde aos casos de infecção sequiencial pelo vírus do dengue 
apresentando $\mathrm{FHD} / \mathrm{SCD}$, os anticorpos preexistentes, obtidos quando da infecção prévia por outro sorotipo viral, não neutralizam o segundo vírus infectante de tipo diferente $\mathrm{e}$ amplificam a infecção, facilitando a este novo sorotipo infectante a infecção maciça de macrófagos e o desenvolvimento de FHD/SCD.

O segundo grupo de pacientes de risco para $\mathrm{FHD} / \mathrm{SCD}$ são lactentes que receberam, intra-útero, anticorpos maternos contra dengue. Com o passar dos meses, esses anticorpos, que apresentam diminuição progressiva, atingem níveis sub-neutralizantes. No caso de infecção destes lactentes pelo mesmo sorotipo do vírus do dengue que causou a infecção materna e, na presença destes anticorpos sub-neutralizantes, ocorreria o fenômeno de facilitaçáo, com a penetração de mais vírus em macrófagos. Deste modo, os pacientes, nestas condiçóes de superinfecção pelo vírus dengue, ficam mais susceptíveis ao desenvolvimento da FHD/SCD.

Acredita-se que indivíduos com FHD/ SCD possuam populações de macrófagos maciçamente infectadas e produzam viremias elevadas. A presença aumentada de moléculas HLA classes I e II nos macrófagos apresentando antúgenos facilita o reconhecimento de múltiplos epitopos virais pelos LT auxiliadores e citotóxicos.

Os antígenos do vírus dengue expressos na membrana macrofágica induzem fenômenos de eliminação imune por LT auxiliadores e citotóxicos. Os macrófagos, ativados pelos linfócitos e agredidos ou lisados pelas células citotóxicas, liberam tromboplastina, iniciando fenômenos da coagulação e proteases ativadoras do complemento, causando lise celular e choque. OTNF-, de origem macrofágica e linfocitária, encontra-se em níveis séricos elevados nos casos graves de $\mathrm{FHD} / \mathrm{SCD}$ e afeta células inflamatórias e endoteliais, o que contribui para a trombocitopenia, induz IL-8, estimula a liberação de histamina pelos basófilos e aumenta a permeabilidade vascular. A IL-6 sérica elevada, observada em alguns casos graves de FHD/ $S C D$, provavelmente induz a hipertermia apresentada por esses pacientes. Também, anafilotoxinas como $\mathrm{C} 3 \mathrm{a}$ e $\mathrm{C} 5 \mathrm{a}$, leucotrienos, histamina e o fator inibidor do ativador do plasminogênio (impede a fibrinólise e leva à deposição de fibrina intravascular) encontramse presentes por curto tempo na FHD/SCD.

A cepa do vírus da dengue infectante nos casos de infecção secundária é reconhecida como provável fator determinante para o aparecimento de FHD/SCD. Também observase, nessas epidemias de dengue, agravamento clínico dos casos com a progressão do surto, sugerindo o aumento da virulência do microorganismo após passagens sucessivas em seres humanos.

Finalmente, fatores do hospedeiro têm papel reconhecido no desenvolvimento de $\mathrm{FHD} /$ SCD. Na epidemia de dengue hemorrágico cubana, em 1981, observou-se o maior número de casos em brancos e relacionou-se ainda a anemia falciforme, diabetes mellitus, doenças reumáticas e asma brônquica como fatores de risco. Outros fatores genéticos como alguns haplótipos HLA relacionam-se à gravidade dos casos.

Portanto, a FHD/SCD tem como base fisiopatológica uma resposta imune anômala envolvendo leucócitos, citocinas e imunocomplexos, causando aumento da permeabilidade por má função vascular endotelial, mas sem destruiçáo do endotélio, com extravasamento de líquidos para o interstício, causando queda da tensão arterial e manifestações hemorrágicas, associadas à trombocitopenia. Conseqüente a estas manifestaçōes surgem hemoconcentração com redução da volemia, má perfusão tissular, hipóxia e acidose lática. Nas análises microscópicas de materiais de necrópsia observase edema perivascular com grande extravasamento de hemácias $\mathrm{e}$ infiltrado rico em células linfomonocitárias. Entretanto, não parece haver dano de paredes vasculares.

A FHD/SCD é comum em países do Sudeste Asiático e Oceano Pacífico Ocidental, onde essa virose ocorre endemicamente, com circulação simultânea de mais de um tipo viral. Nesses locais, a doença acomete, mais 
comumente, crianças. Atualmente, no Brasil, vive-se essa situação com a circulação simultânea dos vírus do dengue sorotipos 1 e 2 . Entretanto, em surtos de FHD/SCD ocorridos nas Américas e particularmente no Brasil, os doentes foram, predominantemente, indivíduos adultos de ambos os sexos. Uma seqüência de infecçóes por dengue foi claramente definida como fator determinante de risco para FHD/SCD. Em 1981, na epidemia de FHD/SCD ocorrida em Cuba, isolou-se dos pacientes o sorotipo 2, quatro anos após a ocorrência da epidemia pelo sorotipo 1. Na ocasião, determinou-se que o risco de FHD/SCD em infecção secundária seria aproximadamente 100 vezes maior do que em uma primo-infecção.

Mais recentemente, em 1997, ocorreu em Santiago de Cuba uma epidemia de dengue pelo sorotipo 2 (cepa Jamaica) com 2.409 casos notificados, sendo 205 de FHD/SCD. Nesta epidemia, as características clínicas apresentadas pelos pacientes diferiram da epidemia anterior (1981) e assemelharam-se em muito à do Brasil, que tem sido causada pela mesma cepa (Jamaica) de DEN-2. Os casos notificados em Santiago de Cuba apresentaram freqüência maior de encefalite e miocardite. $\mathrm{Na}$ mesma série, as formas brandas do dengue foram mais freqüientes em crianças e a $\mathrm{FHD} / \mathrm{SCD}$ não foi notificada nesta faixa etária.

\section{Definição de Casos}

A grande dificuldade de classificação dos casos de dengue hemorrágico geralmente ocorre pela insuficiência de dados na história clínica, ausência dos resultados de hematócrito e da quantificaçáo đo número de plaquetas.

Para acompanhamento do paciente, pela própria dinâmica da doença, ele deve receber um diagnóstico provisório em cada estágio. A classificação diagnóstica definitiva deverá ser feita por ocasiāo do encerramento do caso. Por isto, sugere-se o estadiamento clínico abaixo. Devido ao processo ser dinâmico, o paciente poderá ser classificado em um estágio de FHD/ SCD e evoluir, posteriormente, para outro:

- Grupo A- Febre acompanhada de outros sinais e sintomas inespecíficos e prova do laço positiva;

- Grupo B- Febre acompanhada de outros sinais e sintomas inespecíficos, e de manifestações hemorrágicas espontâneas;

- Grupo C- Febre acompanhada de outros sinais e sintomas inespecíficos, de um ou mais dos sinais de alerta mencionados no item Triagem dos Casos e manifestaçōes hemorrágicas;

- Grupo D-Choque.

Para fins de notificação de caso suspeito de dengue hemorrágico, devem ser utilizados os seguintes critérios: (i) situação epidemiológica; (ii) história de febre; (iii) manifestação hemorrágica; (iv) síndrome de choque; (v) plaquetopenia e (vi) hemoconcentração.

Caso confirmado clinicamente de febre hemorrágica do dengue (FHD) é aquele em que todos os critérios abaixo estão presentes:

- Febre ou história recente de febre há 7 dias ou menos;

- Tendência hemorrágica: prova do laço positiva, presença de petéquias, equimoses, púrpura, sangramento do trato gastrointestinal ou outros sangramentos;

- Plaquetopenia (plaquetas $100.000 / \mathrm{mm}^{3}$ ), e

- Aumento do hematócrito em $20 \%$ sobre o basal na admissão(2), ou queda do hematócrito em $20 \%$ após o tratamento, ou efusão plasmática (derrame pleural, ascite e hipoproteinemia).

Um caso clínico típico de FHD ocorreu com a paciente H. F. C., de 60 anos:

$A$ paciente estava bem $e$, abruptamente, comegon a apresentar febre, que no primeiro dia chegou a ser de $39,4^{\circ}$ C. No primeiro dia da doenca também apresentou mialgias e intensa astenia.

Por esses motivos, no segundo dia da doenca

(2) Se houver dosagem de hemoglobina, pode ser usado o índice hematócrito/hemoglobina, que quando maior que 3,5 indica hemoconcentração (isto não é válido quando se calcula o valor da hemoglobina a partir do hematócrito). 
procurou o médico do Posto de Saside práximo à sua residência, que suspeitou de infeccấo viral pelo vírus dengue, após afastar clinicamente infeccão urinária e leptospirose. Nesta consulta, a propa do laco foi negatipa, e a paciente recebeu a orientafão de manter repouso, dieta lipre com bastante líguidose uso de anti-térmicos (contra-indicou o uso de ácidoacetil-salictico).

Naquela ocasiá̃ foi marcado o retorno da paciente ao Posto de Saúde dentro de dois dias ( $4^{\circ}$ dia de doenfa). Neste dia, o Médico anotou que a paciente referiu ter acordado sem febre e passou a manhã sentindo-se bem melhor até a hora do almogo, apesar de continuarem as mialgias $e$ a astenia. Entretanto, antes do borário do almogo, passou a apresentar dor abdominal localizada no bipocóndrio direito de moderada intensidade. Quando da consulta (às 15:00h), a paciente apresentapa petéquias no ombro esquerdo, a propa do lago foi positiva e ela apresentapa hipotensão postural (deitada: TA de 100x85mmHg e em pé, TA de $80 x 85 \mathrm{mmHg}$ ). Nesta segunda consulta a hemoglabina era de $13,8 \mathrm{~g} / \mathrm{dl}$; o bematócrito de $58 \%$ (indice hematócrito/hemoglobina $=4,2$ ) e as plaquetas foram apaliadas pelo método de Fonio e com valor de $60.000 / \mathrm{mm}^{3}$. Outra amostra de sangue foi colbida e conservada a $-70^{\circ} \mathrm{C}$ para isolamento viral.

Com esses indicadores clínicas e laboratoriais a paciente passou a receber soro fisiológico, penoso $(10 \mathrm{ml} / \mathrm{kg} / \mathrm{h})$ e foi transportada ao Centro de Saside, onde estapa adaptada a Unidade de Internacáo para casos suspeitos de dengue bemorrágico. $A$ paciente, ao chegar ao Centro de Sauide/Unidade de Internacão, tepe o polume a ser administrado aumentado para $20 \mathrm{ml} / \mathrm{kg} / \mathrm{h}$. Na noite do $4^{\circ}$ dia de doenfa, o médico-plantonista observou "marcante redufão do murmúrio pesicular na base do pulmáo direito", e anotou que havia dor abdominal intensa localizada no bipocóndrio direito, à palpação superficial. A partir das 22:30h, a diurese foi de $0,6 \mathrm{~m} / \mathrm{kg} / \mathrm{h}$.

No dia seguinte ( $5^{\circ}$ dia de doenfa), a paciente continuapa com dor no hipocóndrio direito à palpação, e o $R x$ de tórax mostrava pequeno derrame na base do pulmão direito.

Com instituifão do esquema de repasigão bidrica (penosa e oral), o bematócrito sofreu redugão progressiva e, no final da tarde do $5^{\circ}$ dia, era de $40 \%$ e as plaquetas foram contadas em $50.000 / \mathrm{mm}^{3}$. Durante o periodo de internafáo a paciente não apresentou fezes pretas, sangramento paginal ou outras hemorragias (exceto as petéquias no ombro esquerdo, mos sem o aparecimento de outras sufusóes). A propa do lafo na tarde no $5^{\circ}$ dia foi assinalada como negativa.

Na tarde do $\sigma^{0}$ dia a paciente recebeu alta, com a recomendação de manter o repouso durante 10 dias, e a ingesta oral de líquidos. $O R x$ de tbrax foi normal. O hematócrito de saida foi de $40 \%$, plaquetas de $70.000 / \mathrm{mm}^{3}$ e a prova do lafo era negatipa. Uma uiltima amostra de sangue foi colbida às 16:00h, e o soro encaminbado para a realizacão do exame MAC-ELISA (IgM) e inibifão de bemaglutinação $(I H$, com antígenos de sorotipos do virus dengue, virus pacinal da febre amare la e outros Flavivirus). Posteriormente, o caso foi encerrado com a anotafão dos seguintes resultados sorológicose pirologico: (i) IgM - positiva antidengue; (ii) IH para DEN-2 com título recíproco de 160 e titulo recíproco de 20 para $D E N-1$, sendo negatipa para: DEN-3, DEN-4, 17D (víms pacinal da febre amarela) e oxtros Flavivirus $e$ (iii) isolamento do Dirus DEN-2 em canundongos recém-nascidos $e \mathrm{em}$ células C6/36 (da amostra coletada no quarto dia da doenfa).

\section{Triagem dos Casos}

Nos casos de epidemias de dengue sugere-se que sejam realizados esforços para organizar e envolver toda a rede de saúde. $\mathbf{O}$ atendimento dos doentes deve ser deslocado para as Unidades Básicas, onde esses pacientes terão a oferta de pelo menos duas consultas, uma inicial e outra 48 a $72 \mathrm{~h}$ após.

Por ser o tratamento bastante simples, sugere-se que todas as unidades básicas de saúde sejam dotadas de soro fisiológico e equipamento para iniciar a hidratação venosa nos pacientes que tiverem hipotensão ou grande elevação dos níveis de hematócrito. Só deverão ser referenciados para unidades de emergência ou intermediárias os pacientes que necessitarem de hidratação venosa e observação continuada. Por 
isso, também as unidades devem ser dotadas de pessoal com qualificação para realizar prova do laço e microhematócrito.

Nos casos de dengue, independente da forma clínica, a rotina a ser seguida quando os pacientes chegam à Unidade de Saúde é particularmente importante.

Todos os pacientes que procuram o sistema de saúde deverão ter uma história clínica e epidemiológica sucintamente registrada no prontuário ou no boletim de atendimento $\mathrm{e}$ exame físico constando de pelo menos: (i) a medida da tensão artérial (TA) em duas posiçóes (deitado e em pé, preferencialmente, ou sentado); (ii) a frequiência por minuto do pulso radial; (iii) prova do laço(3); (iv) descrição das coloraçóes das mucosas, grau de hidratação e tempo de enchimento capilar(4). O exame físico deve ser completado com a ausculta cárdiopulmonar e palpação do abdome (enfatizando a presença de dor e visceromegalias), assim como a descrição de exantema e manifestações hemorrágicas, cutâneas ou não.

Os pacientes que necessitam de maior atenção do sistema de saúde são os que têm dengue e apresentam história patológica pregressa de alergias (principalmente asma brônquica), anemia falciforme, diabetes mellitus, doenças autoimunes, doenças severas do aparelho cardiovascular e respiratório; esses pacientes e todos aqueles que tiverem manifestaçóes hemorrágicas ou hipotensão arterial devem ser observados com maior cuidado e frequiência. A avaliação deve ser completada com a coleta de amostra sangǘnea pelo menos para o hematócrito, contagem das plaquetas e exame(s) sorológico(s) e virológico, no mesmo dia da consulta ou posteriormente (após o $4^{\circ}$ dia da doença no caso de exames sorológicos).

Os pacientes que apresentem um ou mais sinais de alerta, listados abaixo, devem permanecer sob tratamento e observação rigorosa nas 24 horas seguintes, pois correm grande risco de desenvolver Síndrome de Choque do Dengue.

\section{Sinais de Alerta}

- dor abdominal intensa e contínua;

- vômitos persistentes;

- hepatomegalia dolorosa;

- derrames cavitários (pleural e/ou abdominal);

- sangramentos importantes;

- hipotensão arterial (TA sistólica $\leq 80 \mathrm{mmHg}$ se $\leq 5$ anos de idade; TA sistólica $\leq$ $90 \mathrm{mmHg}$ se $>5$ anos de idade);

- diminuição da pressão diferencial (TA sistólica - TA diastólica $\leq 20 \mathrm{mmHg}$ );

- hipotensão postural (TA sistólica deitado TA sistólica em pé > $10 \mathrm{mmHg}$ );

- diminuição da diurese;

- agitação ou letargia;

- pulso rápido e fraco;

- extremidades frias;

- cianose;

- diminuição brusca da temperatura corpórea associada à sudorese profusa, taquicardia e lipotímia e

- aumento do hematócrito (com variação de $20 \%)(5)$.

\section{Recomendações}

1. No período de queda da temperatura corpórea, os pacientes que não apresentam manifestações hemorrágicas ou qualquer outro

(3) Todo o Grupo Técnico enfatizou a necessidade de treinamento da equipe na realizaçáo da prova do laço e alguns membros consideraram que a duração do teste deve ser de 3 (três) minutos e não de 5 (cinco) minutos, porque com esta última duraçáo o número de casos falsos-positivos é maior e muitos pacientes referem extremo desconforto. A tensáo arterial (TA) média deve ser mantida durante toda a prova do laço e corresponde ao quociente da divisão da (TAsistólica +TAdiastólica)/2 e o tamanho e largura do manguito deve ser adequado para a idade, peso e a circunferência do braço do paciente. A prova é positiva quando 20 ou mais petéquias forem formadas, abaixo do manguito, em área correspondente no braço a $\pm 2,3 \mathrm{~cm}^{2}$ (ou a área de uma polpa digital);

(4) À descompressão da polpa digital da região palmar ou lóbulo da orelha a coloração volta ao normal após tempo inferior a dois segundos; quanto maior for o tempo, maior é a evidência de hemoconcentração.

(5) Verificar observação sobre o índice hematócrito/hemoglobina no item Definição de Casos. 
sinal de alerta listado acima e que evoluam com melhora progressiva do estado geral, retorno do apetite e regressão dos sintomas da fase aguda, deverão ser orientados a permanecer em casa. Se necessário, farão uso de hidrataçáo oral e antitérmicos. Nesses casos é recomendável entregar as recomendações assinaladas no Anexo I ao paciente ou familiar.

2. A classificação correta do paciente, uma observação clínica acurada, orientação adequada e uma conduta terapêutica oportuna e correta são fatores essenciais para uma boa evoluçáo do caso. No exame físico, a prova do laço deve ser realizada em todos os pacientes, bem como a verificação da existência de hipotensão postural (medir TA com o paciente deitado e em pé).

\section{Diagnóstico Laboratorial}

A comprovação laboratorial de infecçōes pelo vírus dengue é feita por métodos virológicos e sorológicos.

Os métodos virológicos compreendem o isolamento viral e a deteç̧ão de antígenos virais. $\mathrm{O}$ isolamento do vírus pode ser feito nos seguintes sistemas: culturas de células de mosquitos e camundongos recém-nascidos. Sangue, soro e fragmentos de órgáos, bem como macerados de mosquitos, são os espécimes mais utilizados com este objetivo. $\mathrm{O}$ sangue para isolamento viral deve ser colhido até o $5^{\circ}$ dia de doença. Quando o espécime é um tecido, deve ser preparado para o exame o mais precocemente possível após a morte do paciente. Esses materiais (prefere-se sangue total ao soro) deverão ser mantidos a $4^{\circ} \mathrm{C}$ e enviados ao laboratório em, no máximo, 12 horas, onde deverão ser preservados a $-70^{\circ} \mathrm{C}$ ou em temperaturas inferiores. A detecção de antígenos virais a partir de soro ou tecidos pode ser feita pelo uso da reação da polimerase em cadeia (PCR) e/ou métodos imunohistoquímicos.

Os testes sorológicos representam os métodos mais simples e rápidos de confirmar o diagnóstico clínico de infecção pelo vírus dengue. Quando o isolamento viral não é possível, os testes sorológicos servem como meio de diagnóstico alternativo. Os testes convencionais de fixação do complemento (FC), inibição da hemaglutinação (IH) e neutralização de plaques (NtRP) em cultivos celulares, embora adequados $\mathrm{em}$ termos de sensibilidade (IH) e especificidade (FC e NtRP), são realizados em poucos laboratórios de referência. Os testes de IH e a FC permitem a diferenciação das respostas imunológicas a infecções primárias e secundárias, enquanto a NtRP permite o reconhecimento dos Flavivirus envolvidos na resposta secundária.

Em uma infecção primária por dengue, os títulos de anticorpos elevam-se lentamente até um nível moderado e são relativamente monoespecíficos (ou seja, o título é mais alto contra o sorotipo do dengue infectante que contra outros Flavivirus). Nas infecçóes secundárias, o título de anticorpos eleva-se rapidamente a níveis muito altos $(\mathrm{IH} \geq 1280)$ e há reação com uma ampla variedade de Flawivirus. Estes métodos (IH; FC e NtRP), no entanto, não permitem discriminar anticorpos IgG de IgM e necessitam de amostras pareadas para a confirmação diagnóstica (mediante elevação $\geq$ a quatro vezes no título sérico do soro de convalescença).

Os métodos modernos, por discriminarem IgM, permitem que o diagnóstico seja feito precocemente, com uma única amostra sérica. Anticorpos IgM antidengue desenvolvemse rapidamente e, pelo $5^{\circ}$ dia, $80 \%$ dos casos (resposta primária e secundária) têm anticorpos IgM detectáveis, os quais em média perduram de 60-90 dias após $q$ início da infecção. Os testes mais utilizados são os imunoenzimáticos, principalmente o de captura de IgM (MACELISA). Para interpretação de um resultado de MAC-ELISA, é importante considerar: (i) uma única amostra positiva não significa necessariamente que o quadro atual seja decorrente de infecção por vírus do dengue, podendo esta infecção ter ocorrido há 2 ou 3 meses; (ii) amostras de soro colhidas precocemente, isto é, antes do quinto dia do início dos sintomas, podem não apresentar níveis de IgM detectáveis e (iii) no caso da resposta imune a uma infecção secundária, pequena 
porcentagem de pacientes (em torno de $5 \%$ ) não produz níveis detectáveis de IgM.

Os materiais encaminhados ao laboratório de referência de cada Estado da Federaçáo devem acompanhar-se das seguintes informaçóes: nome completo do paciente, idade, sexo, endereço e local onde foi colhida a amostra (inclusive para envio do resultado do teste), data do início dos sintomas e data da tomada da amostra. Deve-se enfatizar que a confiabilidade dos resultados dos testes laboratoriais depende dos cuidados durante a coleta, manuseio, acondicionamento e envio das amostras.

\section{Tratamento}

A assistência ao paciente com dengue é extremamente simples. Usa-se, terapeuticamente, na grande maioria dos casos, apenas anti-térmicos, analgésicos e soluções de hidratação, sejam elas de uso oral ou venoso. A principal dificuldade é saber a via a ser utilizada e a dose em cada situação.

Chama-se a atenção para a dinâmica da doença e suas características clínicas. As formas graves surgirão durante os dois primeiros dias de defervescência da febre, em geral entre o $4^{\circ}$ e $6^{\circ}$ dia de doença - exatamente no momento em que a vigilância sobre o paciente decresce e, assim, pode ser a fase de maior risco para o paciente. Por isso, há necessidade de orientar o enfermo, seus familiares e a equipe de saúde sobre esta circunstância.

$\mathrm{Na}$ Unidade de Saúde e no domicílio deve ser incentivado o uso de mosquiteiro durante o período diurno (quando a fêmea do Ae. aegypti faz o repasto sangǘneo), porque a presença de indivíduo virêmico poderá ampliar a transmissão do vírus do dengue. Algumas recomendações são extremamente relevantes durante a avaliação e/ou acompanhamento dos pacientes, especialmente a manutenção de repouso do paciente e a ingesta oral de líquidos, sucos e/ou soro caseiro.

A terapêutica a ser administrada deve ser pela via oral, preferencialmente, e/ou venosa. A administração de medicamentos pela via intramuscular é contra-indicada. Em caso de:

Febre: recomenda-se o uso de antitérmico. Entretanto, na grande maioria dos casos, na fase inicial da doença, a febre costuma ser elevada e pode náo haver normalização da temperatura com o uso da medicação. $O$ intervalo entre as doses deve ser o suficiente para manter a temperatura abaixo de $38,5^{\circ} \mathrm{C}$, na dependência do que for suportável pelo paciente. Usa-se habitualmente paracetamol ou dipirona. Há contra-indicação para o uso do ácido-acetil-salicílico (aspirina), pelo potencial de agravamento do quadro hemorrágico. A mesma contra-indicação aplica-se aos demais antiinflamatórios não-hormonais, mesmo quando usados pela via intra-muscular.

Dores (cefaléia retro-orbitária, mialgias e artralgias): as mesmas drogas utilizadas como anti-térmicas devem ser utilizadas como analgésicas. A cefaléia pode ser minorada com bolsa de gelo na cabeça. Nos casos graves de dor, quando não há resposta aos analgésicos citados acima, utilizar a associação de codeína + paracetamol (comprimidos com respectivamente $30 \mathrm{mg}$ e $500 \mathrm{mg}$, os adultos podem usar até um comprimido a cada quatro horas). Mesmo assim, pode não haver o desaparecimento marcante dos sintomas álgicos. Neste caso, ou quando houver doenças autoimunes associadas (artrite reumatóide, lupus, entre outras), deve-se usar cloridrato de tramadol ou meperidina. Contudo, a indicação de tramadol ou meperidina não foi consensual, porque ambas têm como para-efeito a hipotensão arterial, em especial em pacientes hipovolêmicos. Também não foi consensual a indicação do uso do ácido mefenâmico.

Manifestaçóes digestivas (náuseas, vômitos e diarréia): não costumam ser dominantes no quadro da doença $e$, freqüentemente, não necessitam de tratamento específico. Se houver necessidade, pode-se usar para náuseas e vômitos os anti-eméticos usuais (metoclopramida ou alizaprida) e para a diarréia reforçar a hidratação com soluções salinas orais. É contra-indicado o uso de anti-diarréicos. Pacientes com história pregressa de gastrite ou 
úlcera péptica ou que apresentarem reativação ou agravamento destas patologias devem receber bloqueador $\mathrm{H}_{2}$ : (i) ranitidina, oral; adultos comprimido de $150 \mathrm{mg}$, duas vezes por dia $\mathrm{e}$ crianças - comprimidos efervescentes ou xarope sendo a dose total diária de até $150 \mathrm{mg}$, dependendo do peso ou (ii) cimetidina, oral; adultos - $800 \mathrm{mg}$ por dia, à noite, ou dividida em duas doses, pela manhã e a noite. A ranitidina também poderá ser usada rotineiramente em casos de dengue hemorrágico, com a justificativa de reduzir o risco de úlceras de "stress".

Prurido e exantema: aparecem em 30 a $40 \%$ dos pacientes. O prurido surge na fase de defervescência da síndrome febril e localiza-se com maior intensidade nas regiōes palmoplantares. Nesses casos utiliza-se os antihistamínicos usuais (dexclorfe amina, terfenadina ou cetirizina), mas nem sempre com bons resultados. Medidas locais como compressa de gelo sobre as regiōes mais pruriginosas podem causar melhora temporária. O exantema não necessita de tratamento.

Hipotensão arterial: instituir imediatamente a hidratação venosa, de preferência puncionando a veia basilar. A hidratação deve ser iniciada no local onde o paciente estiver sendo atendido. Por isso, toda Unidade de Saúde deve ter um "Kit" para este procedimento. Utilizar soro fisiológico a $0,9 \%$ na dose de 10 a $20 \mathrm{ml} / \mathrm{kg} / \mathrm{h}$, de forma rápida. Isto pode ser feito com grande margem de segurança, se houver um médico monitorizando a tensão arterial, o pulso, a turgência jugular e a ausculta cárdio-pulmonar. Havendo sobrecarga momentânea de volume, a velocidade de infusão deve ser reavaliada e, se necessário, transportar o paciente para uma Unidade de Saúde com melhores condiçóes de atendimento.

Para adultos, após a estabilização da tensão arterial deve-se manter a infusão de $30 \mathrm{ml} /$ $\mathrm{kg} / \mathrm{dia}$, com $1 / 3$ de solução salina (soro fisiológico preferencialmente, ou Ringer lactato) e $2 / 3$ de soro glicosado a $5 \%$ ou de solução glicossalina. A alimentação oral deve ser mantida. Em caso de lactente, o leite materno deve continuar sendo oferecido e as unidades de saúde devem buscar mecanismos para apoiar e incentivar a amamentação materna.

É necessária a vigilância constante sobre a tensão arterial (aferida preferencialmente na seguinte seqüência: com o paciente deitado e em pé), o pulso, a turgência jugular, o enchimento capilar, a ausculta cardíaca e pulmonar e, sobretudo, a diurese (manter acima de $0,5 \mathrm{ml} / \mathrm{kg} / \mathrm{h}$ ). A evolução do paciente com dengue hemorrágico é extremamente dinâmica e, também por isto, durante a fase de administração venosa de soluçóes hidroeletrolíticas e/ou hemoderivadas deve ser mantida rigorosa vigilância dos sinais vitais, especialmente de sinais associados a hiperhidratação e edema pulmonar, ocorrências frequientes em unidades de atenção ao paciente com dengue hemorrágico. $\mathrm{O}$ acompanhamento ambulatorial e durante a internação estão apresentados nas árvores de decisão expostas, respectivamente, nos Anexos II e III.

Nas crianças e adultos, sem ingesta de líquidos especialmente após a primeira diurese observada durante ou após a reposição da volemia, recomenda-se a reposição de potássio (2 a $3 \mathrm{mEq} / \mathrm{kg} / 24 \mathrm{~h}$ ), acrescentado na solução de soro fisiológico.

Durante a reposiçáo da volemia e na fase de manutenção o volume total de líquidos nas $24 \mathrm{~h}$, ou por período deve ser ajustado, estando o paciente febril com temperatura $>38^{\circ} \mathrm{C}$ (aumentar $\mathrm{em} \pm 6 \%$ o volume calculado), diarréia (repor $50 \mathrm{ml}$ de líquidos/evacuação), vômitos (repor o volume perdido) e/ou taquipnéico.

Critérios de alta dos pacientes graves: os pacientes (dos grupos $\mathrm{Ce} \mathrm{D}$, citados no item Definição de Casos) terão alta da unidade de internação quando apresentarem os seguintes indicadores: (i) afebril por mais de 24h; (ii) sinais vitais estáveis; (iii) prova do laço negativa; (iv) plaquetas acima de $20.000 / \mathrm{mm}^{3}$; (v) recuperação do apetite (a anorexia ć associada quase sempre, especialmente nas crianças, à dor abdominal); (vi) ausência de sangramento ativo; (vii) ausência de hepatomegalia dolorosa; (viii) 
ausência de dor torácica; (ix) face nãoruborizada; (x) reabsorção de derrame(s) cavitário(s) e (xi) nível de consciência conservado. Quando da alta, o paciente deve receber a recomendação de manter repouso relativo, durante oito a quinze dias, de acordo com a situação clínica anterior.

Esse tratamento precoce resulta em boa resposta clínica. $\mathrm{Na}$ grande maioria dos casos de FHD não se deve adotar procedimento invasivo para infusão de líquidos, sendo isto quase sempre desnecessário para o acompanhamento clínico e que pode aumentar o risco de infecção secundária e/ou hemorragias.

\section{Considerações Finais}

O Grupo Técnico julgou conveniente fazer também as seguintes observaçóes e/ou recomendaçōes:

1. Os pacientes com infecção pelo vírus do dengue após a fase de convalescença, habitualmente com duração média de 15 dias, podem fazer doação de sangue, após avaliação pelo médico do Hemocentro, Serviço de Hemoterapia ou Banco de Sangue;

2. Os Hemocentros devem promover discussões e cursos sobre o uso de sangue e hemoderivados em casos de dengue hemorrágico não-responsivos a soluções hidro-eletrolíticas e/ou expansoras, inclusive planejando estratégias no caso de epidemia de dengue hemorrágico;

3. Os Serviços de Saúde devem promover cursos sobre dengue, especialmente sobre diagnóstico e tratamento das formas graves, qualificando a equipe na realizaçāo da prova do laço e outros procedimentos necessários;

4. Os orgáos gestores devem equipar as unidades assistenciais com micro-centrífugas para microhematócrito, e outros equipamentos para a dosagem de hemoglobina e quantificação do número de plaquetas.

\section{Agradecimentos}

O Grupo Técnico agradece aos alunos de Medicina do Programa Especial de Treinamento (PET-Medicina) da CAPESUFBA: Marcelo Martinez, Luiz Serra Azul e também Elenaide Coutinho, Ília Aragão e Marcelo Cunha. Estes alunos não só acompanharam a discussão do Grupo Técnico como colaboraram na digitação e editoração do presente texto, especialmente Marcelo Martinez.

\section{Bibliografia}

1. Antezana, D.; Nobre, A.; Tauil, P. L. Febre amarela e dengue no Brasil: epidemiologia e controle. Revista da Sociedade Brasileira de Medicina Tropical. 27(supl. III): 59-66, 1994.

2. Bhamarapravati, N.; Tuchinda, P.; BoonyapakNavik, V. Pathology of Thailand haemorrhagic fever: a study of 100 autopsy cases. Annals of Tropical Medicine and Parasitology. 61:50010, 1967.

3. Brasil. Ministério da Saúde. Fundação Nacional de Saúde. Manual de Dengue Vigilância Epidemiológica e Atenção ao Paciente. $2^{a}$ ed., Brasília, 1996.

4. Escalante, J.; Gonzalez, J. Aspectos clínicos del dengue hemorrágico en pacientes adultos. Monografia, Hospital Central de Maracay e Universidade de Carabobo, Venezuela, 1990.

5. Figueiredo, L. T. M. Fisiopatogenia da infecção pelo vírus do dengue. Curso sobre dengue: clínica e terapêutica, Sociedade Brasileira de Medicina Tropical, Salvador, Bahia, p. 18, 1997 [mimeog.].

6. Pan American Health Organization-Dengue and Dengue Hemorrahgic Fever in the Americas: Guidelines for Prevention and Control. Scientific publication №548, 1994.

7. Pereira, M. A.; Giorgiew, M. G. Respuesta al tratamento en pacientes adultos con diagnóstico de dengue hemorrágico. Monografia, Hospital Central de Maracay e Universidade de Carabobo, Venezuela, 1990.

8. Rio de Janeiro. Secretaria Estadual de Saúde. 
Dengue: diagnóstico e tratamento. Informe técnico № 3, 1990.

9. Situação de dengue no Brasil. Documento elaborado pela Gerência Técnica de Febre amarela e dengue. Fundação Nacional de Saúde, Ministério da Saúde, p.7, 1997 [mimeog.].

10.Travassos da Rosa, A. P. A.; Travassos da Rosa, E. S.; Travassos da Rosa, J. F. S.; et al. - Os arbovírus no Brasil: Generalidades, métodos e técnicas de estudo. Doc. téc. № 2, Serviço de Arbovírus, Instituto Evandro Chagas, Fundação Nacional de Saúde. Belém, Pará, 1994.

Anexo $\mathbf{l}^{*}$

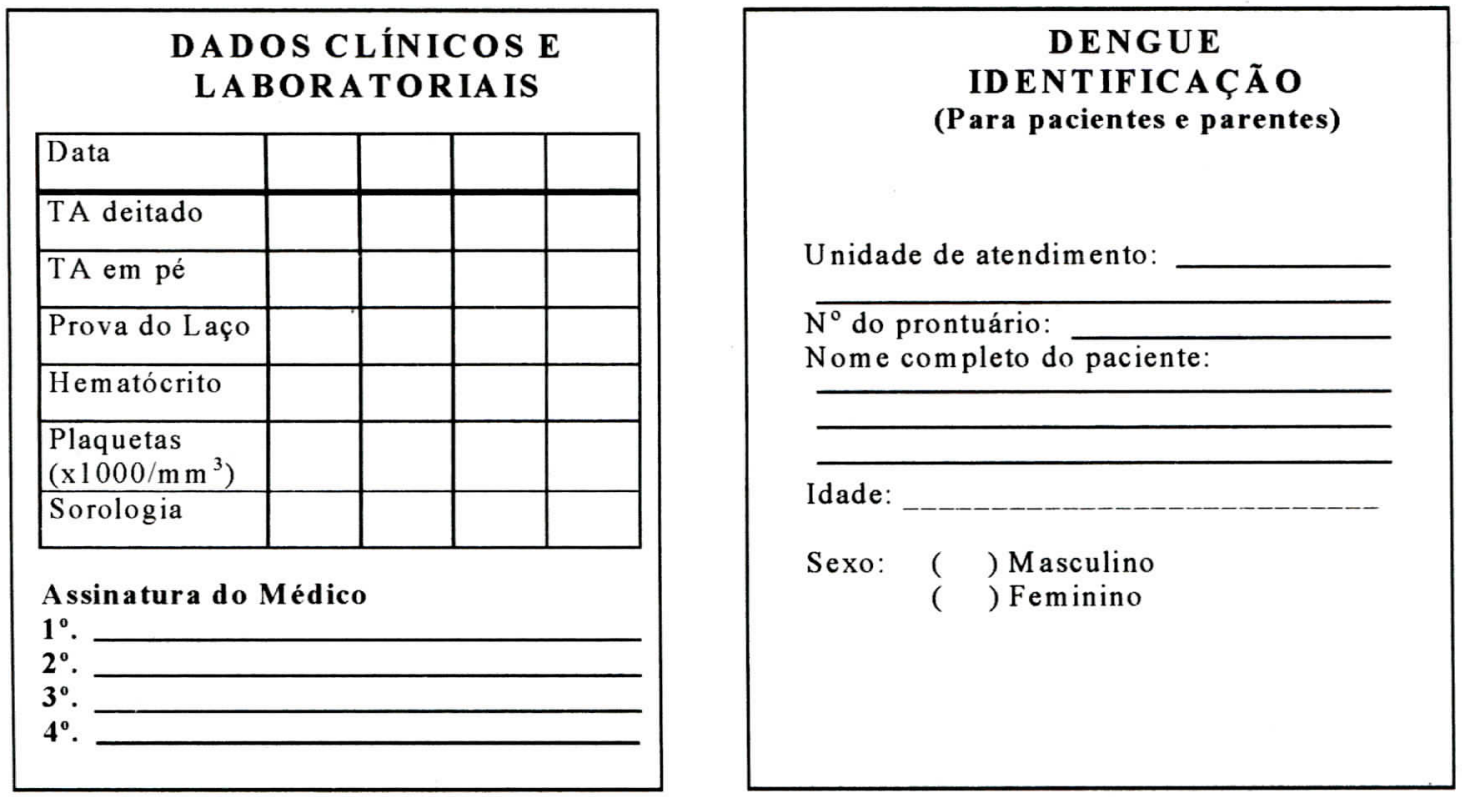

\section{Recomendações para pacientes com dengue e parentes}

As complicações se apresentam geralmente entre o terceiro e o quinto dia da doença e os familiares devem observar o paciente até dois dias após o desaparecimento da febre.

1. Dar muito líquido (água, sucos de frutas, soro caseiro, água de coco, sopas, leite, chá, etc.) e fazer repouso. Para as crianças que mamam no peito não deve ser suspenso o leite materno. As mulheres com dengue podem continuar a amamentação de suas crianças.

2. Procurar atendimento médico, se aparecerem:

- Pontos ou manchas vermelhas ou roxas na pele

- Sangramento de nariz, boca ou outros tipos de sangramento

3. Procurar imediatamente atendimento de emergência, se aparecerem:

- Fezes pretas

- Vômitos freqüentes

- Muito sono ou agitação

- Dor na barriga

- Tontura, vista escura, desmaio

- Pele pálida, fria, seca

- Dificuldade de respirar

4. Siga rigorosamente as orientações acima.

(Local de atendimento:

(parte interna da carteira)

- Adaptado do Anexo 6 do Manual do Dengue: Vigilâneia Epidemiológica • Atençăo ao Doenteministírio da Saúde, 1996 
Anexo II*

Atendimento Ambulatorial do caso suspeito de dengue hemorrágico

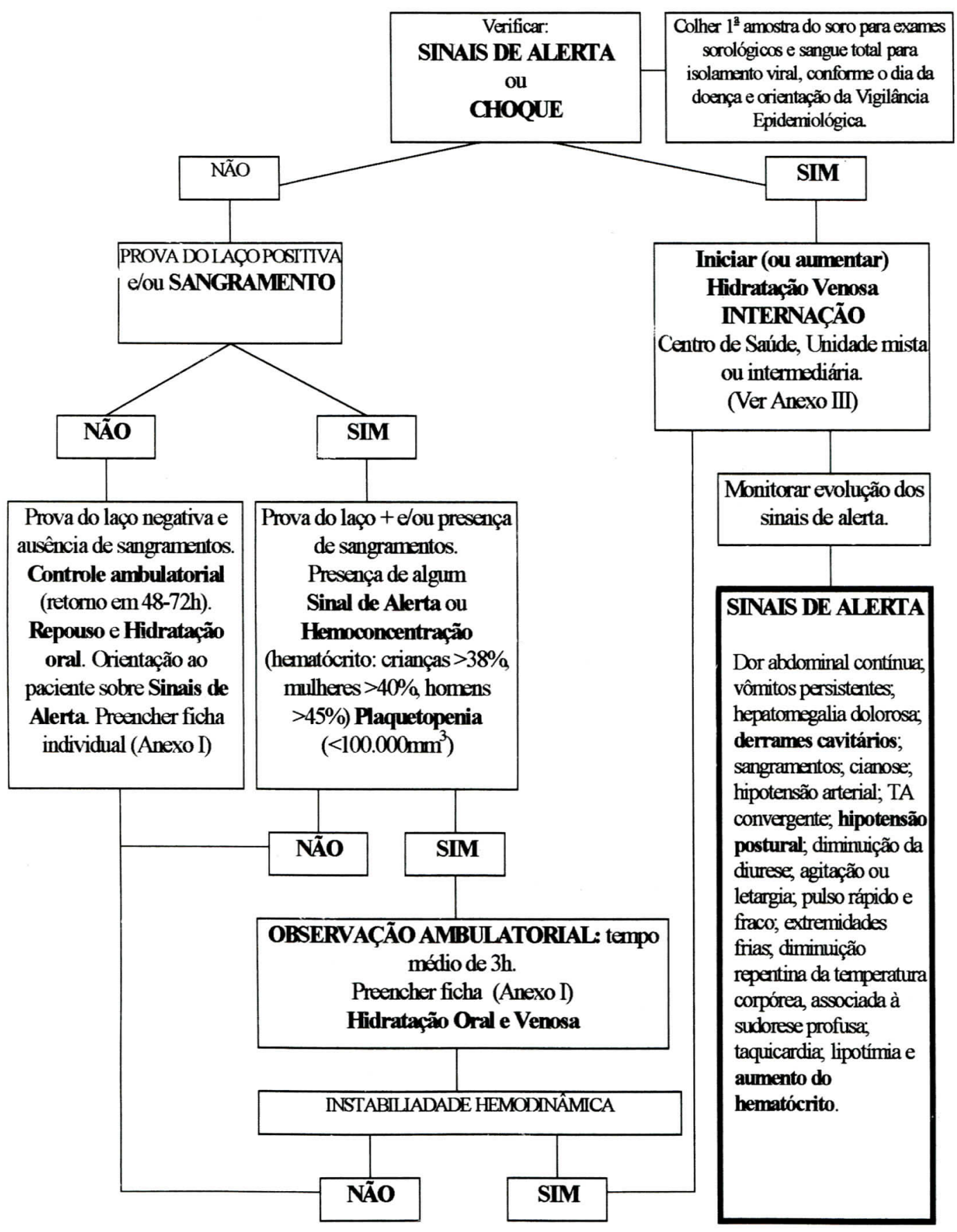

"Revisão do Anexo 6 do Manual de Dengue: Vigilância Epidemiológica e Atonção ao Doonte/Ministério da Saúde, 1996 
Anexo III

Internação: dengue hemorrágico ou choque

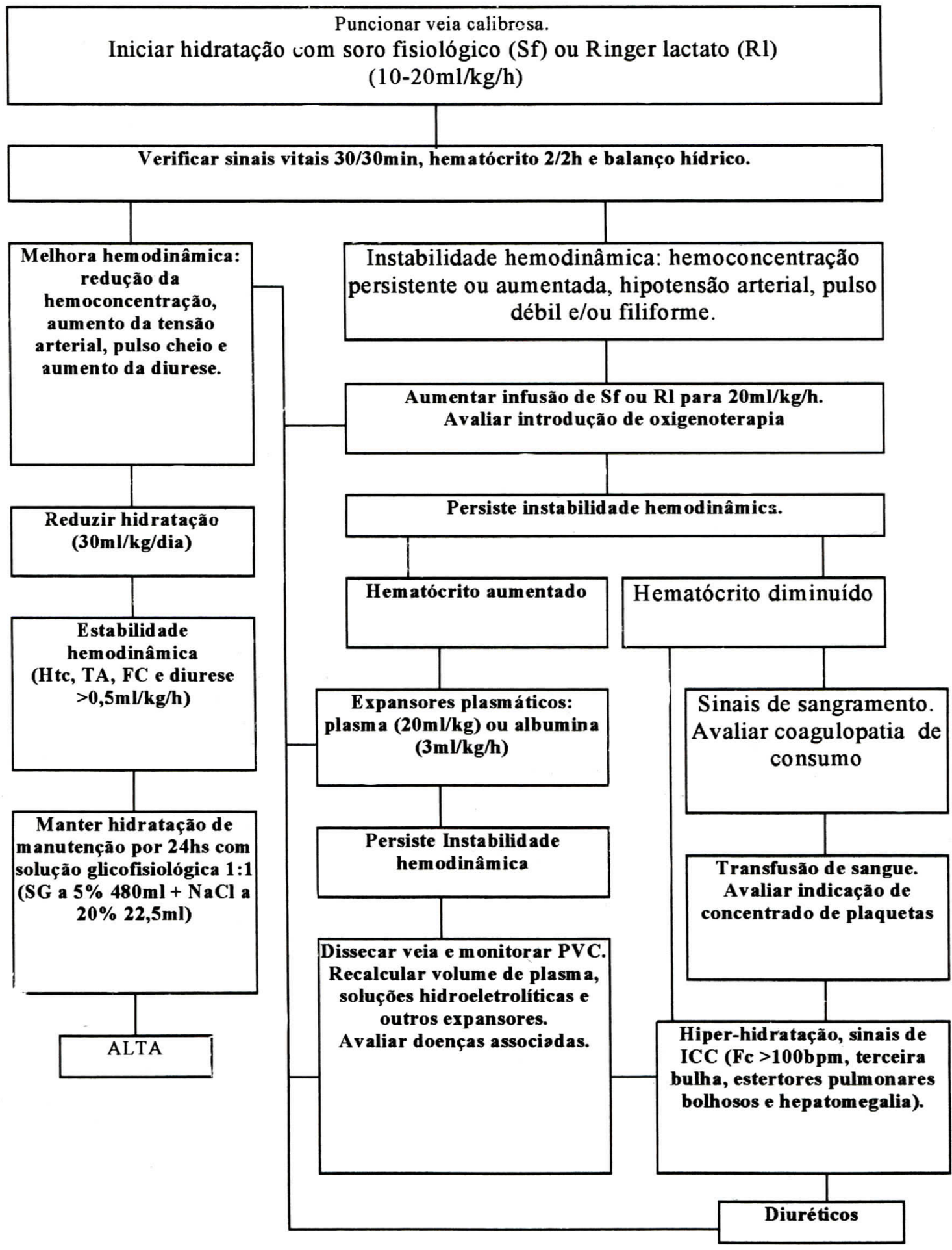

IESUS, VI(2), Abr/Jun, 1997. 